\title{
Estudio Comparado de los Contextos Sociopolíticos de los Movimientos Estudiantiles en Brasil y Venezuela ${ }^{1,2}$
}

\section{Comparative Study of Socio-Political Contexts of Student Movements in Brazil and Venezuela}

\author{
Luis Jesús Teneud* \\ Danuta Estrufika Cantóia Luiz ${ }^{*}$
}

Resumen: El presente trabajo busca comparar los contextos socio-políticos en los cuales se han desarrollado los movimientos estudiantiles universitarios de Brasil y Venezuela. Se hará un resumen histórico del desarrollo político de ambos países durante los siglos XX y XXI, revisando sus ciclos democráticos y dictatoriales cronológicamente, posteriormente se presentará un breve resumen de los momentos y acciones más importantes de los movimientos estudiantiles universitarios de ambos países y sus liderazgos, para finalmente establecer diferencias y semejanzas entre los dos movimientos. La categoría elegida para el estudio es parte de la propuesta de Maria da Glória Gohn para el estudio de los movimientos sociales, esquema conceptual que permite una delimitación y aproximación adecuadas a los movimientos de interés.

Palabras Clave: Contexto Sociopolítico; Movimiento Estudiantil; Movimientos Sociales.

\begin{abstract}
This research seeks to compare the socio-political scenarios in which the university student movements of Brazil and Venezuela have developed. A historical summary of the political development of both countries during the twentieth and twenty-first centuries will be made, comparing their democratic and dictatorial cycles chronologically, then a brief summary of the most important moments and actions of the university student movements
\end{abstract}

\footnotetext{
${ }^{1}$ El presente trabajo fue realizado con apoyo de la Coordenação de Aperfeiçoamento de Pessoal de Nível Superior - Brasil (CAPES) - Código de Financiamento 001

${ }^{2}$ Uma versão preliminar deste texto foi apresentada no "III SIMPÓSIO INTERNACIONAL INTERDISCIPLINAR EM CIÊNCIAS SOCIAIS APLICADAS: Democracia e direitos humanos” realizado em Ponta Grossa- PR, entre 11 a 13 de setembro de 2019 , sendo indicado pelo evento para compor este volume especial da Emancipação (nota do editor).

* Máster en Ciencias Sociales Aplicadas por la Universidad Estatal de Ponta Grossa - UEPG. Graduado en Ingeniería de Materiales de la Universidad Simón Bolívar - Venezuela. Correo: lteneud@gmail.com.

** Doutora e Mestre em Serviço Social pela Pontifícia Universidade Católica de São Paulo. Graduada em Serviço Social pela Universidade Estadual de Ponta Grossa. Professora associada da Universidade Estadual de Ponta Grossa (Curso de Serviço Social e Programa de Pós-graduação em Ciências Sociais Aplicadas). Correo: danutaluiz88@gmail.com.
}

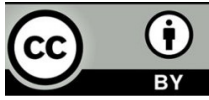


of both countries and their leaderships will be presented, to finally establish differences and similarities between the two movements. The category chosen for the study is part of the approach of Maria da Glória Gohn for the study of social movements, a conceptual scheme that allows adequate delimitation and approximation to the movements of interest.

Keywords: Sociopolitical Scenario; Student Movement; Social Movements.

Recebido em 13/10/2019. Aceito em 23/10/2020.

\section{Introducción}

Un factor muy importante en los cambios que se experimentan en cualquier sociedad, incluso si son de naturaleza política, proviene de los llamados movimientos sociales. Existen diferentes definiciones de movimientos sociales, dependiendo de los autores que tratan el tema y sus referencias epistemológicas, pero al intentar un primer enfoque conceptual, se puede pensar en grupos con un interés común que tienen algún tipo de reclamo ante el poder formal, principalmente al sentir que sus derechos no son garantizados. Al defender estos derechos, son capaces de generar acciones de presión y lograr una mayor conciencia en el entorno social, estos movimientos generalmente interactúan con otros y pueden formar redes de acción, estableciendo objetivos en común.

Dentro de los movimientos sociales, los movimientos estudiantiles revisten gran importancia, ya que han tenido luchas que buscan transformar no sólo su entorno más inmediato, sino la sociedad en general, y se han convertido en referentes de luchas sociales más profundas. En específico, en el entorno latinoamericano se han dado importantes cambios en sistemas políticos y el funcionamiento de las instituciones, principalmente las universidades, respecto al resto del mundo.

Sin embargo, cada país latinoamericano ha tenido sus propios procesos y tiene sus particularidades. Una de las metodologías más detalladas para el estudio de los movimientos sociales es la planteada por Maria da Glória Gohn (GOHN, 1997), que define varias categorías de estudio.

Con el presente estudio se busca comprender el desarrollo sociopolítico de Venezuela y Brasil, establecer sus principales hitos, conocer brevemente la historia e importancia de los movimientos estudiantiles en ambos países, y finalmente determinar las semejanzas y diferencias entre ambos países, estableciendo un marco referencial para el desarrollo de futuros trabajos en el área.

\section{Metodología}

A partir de la comprensión de los movimientos sociales se pasa a sistematizar una propuesta metodológica basada en el estudio de las categorías propuestas por la Profesora Maria da Glória Gohn (1997), la cual apoyará en la presente investigación.

Estas categorías se toman de la obra "La Teoría de los Movimientos Sociales" de Maria da Glória Gohn (1997). Para la autora, los elementos se pueden clasificar como internos y externos. 
Dentro de los factores internos, Gohn (1997) señala: sus demandas, articulaciones, ideología, proyectos, organización y prácticas. Entre las categorías que se pueden definir externamente, se destacan las siguientes: el contexto sociopolítico, sus oponentes, las redes externas (o alianzas) y las relaciones con otras entidades y organizaciones.

Posteriormente, Gohn (1997) reúne algunas de estas categorías proponiendo la siguiente clasificación: Procesos, Utopías, Repertorio, Composición, Principio Articulador Interno, Principio Articulador Externo, Fuerza Social, Ideología, Cultura Política, Organización, Prácticas, Proyecto Social y Político, Identidad, Proyecto Sociopolítico, Opositores, Logros y Derrotas.

Gohn explica la importancia de estudiar el contexto sociopolítico en los movimientos sociales y explica su importancia como factor de cambio social con las siguientes palabras:

Elas representam sempre uma possibilidade de renovação e mudança e conferem aos movimentos os atributos de poder. Se trata de um tipo de jogo de forças em que se disputa não a construção do bem comum (infelizmente) mas a tomada de espaços sobre a produção, gestão e controle de uma infinidade de coisas (bens públicos no caso dos movimentos populares, direitos sociais e trabalhistas, no dos movimentos sindicais, terras no caso dos movimentos agrários e dos índios, direitos sociais que poderão redundar em novos encargos sociais, no caso do movimento das mulheres e dos negros; maior responsabilidade do Estado e cumprimento da legislação trabalhista no caso dos movimentos dos menores etc.) (GOHN, 1997, p. 262).

\section{Contexto Sociopolítico de Brasil y Venezuela: Comienzos del siglo XX}

El inicio del Siglo XX en Venezuela, representa la continuidad del XIX, el poder es dividido entre líderes militares carismáticos (llamados caudillos) que a través de largas campañas desde diversas partes del país se ven sumergidos en continuas guerras hasta que alguno de ellos logra imponerse y llega a Caracas a ejercer la presidencia de la República. El último de estos caudillos, Juan Vicente Gómez, que gobernó el país desde 1908 hasta su muerte en 1935, fue quien llevó a cabo la "modernización" del mismo, acabando con el caudillismo y creando la Academia Militar para lograr la estabilidad política del país.

Es, sin embargo, Gómez un dictador tradicional militar, que no permite la libertad de prensa, que encarcela y lleva hasta la muerte a sus rivales políticos, y que se rodea de importantes intelectuales que defienden la teoría positivista del "Gendarme necesario", idea contraria a la democracia y que sustenta la importancia de que un líder militar imponga el orden en la sociedad para garantizar su desarrollo, esto contrasta con la inspiración de los jóvenes universitarios que, bajo la influencia de la Revolución Rusa y la Reforma de Córdoba, creen en un modelo de sociedad más participativa.

Varios de estos jóvenes lideraron la Generación del 28, cabe destacar que, en el ámbito venezolano, se conoce como "generación" a un grupo de estudiantes que en cierto momento coinciden en la dirigencia estudiantil universitaria y promueven acciones de calle y de protesta, normalmente se les identifica por el año en el cual se ejercen esas protestas, indistintamente del nivel de avance de la carrera en el cual se encuentren, al respecto señala Bernard:

Pero es en 1928 que se desarrollaron los primeros signos de una oposición más articulada al régimen, al irrumpir en las calles de Caracas, manifestaciones de estudiantes organizados en la Federación de Estudiantes de Venezuela, 
los cuales habían tomado como pretexto, la celebración de la Semana del Estudiante para convertirse en portavoces de la sorda protesta de la mayoría capitalina. Estos más tarde denominados "la generación de 1928" con, entre su liderazgo, figuras hoy en día tan conocidas como Jóvito Villalba, Rómulo Betancourt y Raúl Leoni, representaban en realidad, la vanguardia de los intelectuales, trabajadores y venezolanos de clase media, quienes después de 1935, entrarían a formar parte de los primeros partidos políticos del país, y en particular de aquellos que con el tiempo se convertirían en expresión de los dos sectores socio-económicos emergentes para entonces, como lo eran la clase obrera y la burguesía industrial.(BERNARD, 1994; p. 22-23).

Mientras tanto, Brasil comenzó el Siglo XX en medio de una especie de experimento democrático, en el cual, sin embargo, no existía el voto universal y secreto y donde la política del "Café con Leche" regía las elecciones, con una amenaza permanente de revoluciones. Igualmente, en Brasil, se tienen ciertas características que apuntan a un país con algunos principios democráticos, pero con frecuentes revueltas que no dan plena estabilidad al país, además, el ejercicio del voto se ve limitado, al intentar universalizarse, pero no ser secreto. Barile explica la República del "Café con Leche":

El período que va desde 1891 a 1930, es conocido como el de República del Café com Leite, debido a que el gobierno central de la república del Brasil, realizó una política que benefició a los estados de Minas Gerais (Leche) y São Paulo (Café), principalmente en lo que refiere al cultivo de este último principal producto de exportación de ambos estados. El pacto político de la República del Café com Leite se expresó en el acuerdo de Ouro Fino, en 1913, que permitió que la presidencia sea ocupada de manera alternativa, ya sea por un Paulista o un Mineiro. El pacto económico, fue sellado en el año 1906 "Convenio de Taubaté" firmado por los estados de São Paulo, Minas Gerais y Río de Janeiro (BARILE, 2017, p.40).

El año 1930 marca la llegada al poder de Getúlio Vargas en Brasil, a partir de ese momento se inicia una serie de reformas que permitirá el avance de Brasil hacia un estado moderno, con una fuerza armada profesional y con el concurso de diversos sectores, sin embargo, las voces que piden una mayor democratización en la estructura del país, no son escuchadas y la implementación del "Estado Novo" trae consigo el rechazo manifiesto a la participación de aquellos sectores considerados comunistas, y la aplicación de políticas conservadoras.

A la muerte de Gómez, en Venezuela, le sucede su ministro de Guerra y Marina, Eleazar López Contreras, él, y su sucesor Isaías Medina Angarita, darán inicio a una especie de lenta transición a la democracia, garantizando alternabilidad en el poder, elecciones indirectas y mayores beneficios laborales; sin embargo, la lentitud de los cambios, el surgimiento de una clase militar con mayor formación y con aspiraciones de poder y de cambio, y la repentina locura que sufre Diógenes Escalante, candidato presidencial de consenso entre los militares y los partidos políticos con aspiraciones democráticas para las elecciones presidenciales de 1945, visto como alguien capaz de dirigir la transición a la democracia, causan que se interrumpa este proceso con un golpe de estado el 18 de octubre de aquél año. Al respecto se señala:

Los Gobiernos que sucedieron a la dictadura de Gómez habían iniciado una cierta liberalización, pero sin llevar a cabo una verdadera democratización. Las vías de acceso de la sociedad a la política continuaron bloqueadas por 
instituciones tales como el sufragio restringido y la elección indirecta del Congreso y del presidente, y se mantuvieron regímenes oligárquicos en los que el reclutamiento político tenía lugar a través de camarillas, grupos familiares y procedimientos caracterizados por el uso de criterios particularistas y adscriptivos, en los que la posesión de riquezas o los vínculos personales, y el prestigio y la influencia que de ellos se derivaban, eran los principales recursos políticos. (REY, 1991, p. 536-537).

\section{El experimento democrático en Brasil y Venezuela}

Entre 1945 y 1948 gobernó Venezuela una junta compuesta por civiles y militares, liderada por Rómulo Betancourt, joven de 36 años y antiguo líder de la generación del 28, así como fundador del partido de ideología socialdemócrata Acción Democrática (AD). En 1948 se convocan las primeras elecciones realmente democráticas, ganadas por el candidato de $\mathrm{AD}$, el conocido escritor Rómulo Gallegos, quien gobierna apenas unos meses, ya que sufre un golpe de estado de parte de sus antiguos aliados militares en noviembre del mismo año.

También en octubre de 1945, se da un golpe de estado en Brasil, igualmente reivindicando las banderas democráticas y buscando generar cambios que no solo garanticen "modernidad", sino también participación popular en la toma de decisiones importantes. La transición a la democracia en Brasil fue real, realizándose elecciones en el propio año de 1945, las cuales son ganadas por Eurico Gaspar Dutra, apoyado por el Partido Social Democrático (PSD).

Posteriormente, en 1950, Getúlio Vargas vuelve al poder, esta vez por la vía democrática, y su nuevo gobierno, toma un tono más popular y de defensa de los derechos de los trabajadores, reivindicando además la importancia de la participación del Estado en la toma de decisiones económicas y en la redistribución de riquezas, algunas de estas medidas resultaron polémicas para sectores de la sociedad brasileña, principalmente, en el campo militar, llevando a un pronunciamiento en agosto de $1954 \mathrm{y}$ al posterior suicidio del presidente.

Mientras Venezuela vivía una economía floreciente y una situación crítica en cuanto a ciudadanía y derechos políticos, como será explicado en los próximos párrafos, Brasil elegía como presidente a Juscelino Kubitschek (JK), quien tendría una gestión exitosa en el plano económico, principalmente apuntalado por la construcción de Brasilia, la nueva capital del país, generando una importante cantidad de empleos y dinamizando el sistema económico brasileño.

\section{El regreso a la dictadura}

Una junta militar gobernó Venezuela entre 1948 y 1952, los partidos de izquierda: Partido Comunista de Venezuela (PCV) y Acción Democrática (AD) son prohibidos y sus principales dirigentes encarcelados y torturados, enviados al exilio o asesinados. Algunos partidos de centro derecha permanecen en la legalidad, pero también serán prohibidos más adelante: Unión Republicana Democrática (URD) en 1952, tras ganar las elecciones (resultado desconocido por el gobierno) y ser acusado de infiltrar dirigentes de izquierda en sus listas y el partido socialcristiano COPEI en 1957, para evitar una eventual candidatura presidencial de su líder Rafael Caldera. Estas elecciones realizadas en diciembre debilitan la imagen del dictador Marcos Perez Jimenez, siendo derrocado el 23 de enero de 1958 e iniciándose un nuevo periodo democratico en el país caribeño. 
En 1960, Venezuela luchaba por afianzar la naciente democracia, y Brasil parecía tener un sistema democrático sólido, ese año es electo como presidente en Brasil el abogado Jânio Quadros, quien comienza una serie de cambios que generan críticas en varios sectores, sin embargo, es su acercamiento a los gobiernos de izquierda lo que le gana la antipatía del sector militar, obligándolo a renunciar mientras el vicepresidente João Goulart se encontraba en un viaje en el exterior.

Finalmente, Goulart retorna al país y asume la presidencia, no obstante, su poder se ve seriamente limitado tras el regreso al sistema parlamentario, dejando la figura del presidente prácticamente como algo decorativo, un cargo dependiente de las decisiones del Congreso. El gobierno de Goulart fue etiquetado de comunista por diversos sectores conservadores, aprovechando el entorno de la guerra fría y justificando así el golpe de estado del año 1964, sin embargo, una rápida revisión a las políticas aplicadas por Goulart, permite ver la aplicación de políticas como la reforma agraria y los cambios propuestos en educación, pero buscando el desarrollo de Brasil. Igualmente, si bien, se produce un acercamiento a la Unión Soviética, se mantienen las relaciones con Estados Unidos, por lo que se podría hablar más de un Brasil neutro en medio de la Guerra Fría, que de un Brasil comunista.

\section{La democracia venezolana y la dictadura brasileña}

El 23 de enero de 1958 es derrocado Pérez Jiménez y se instala una Junta de Gobierno, en diciembre de ese año se realizan elecciones universales en las cuales participan los cuatro partidos existentes entonces: URD, AD, COPEI y el Partido Comunista de Venezuela (PCV), este último, apoyando al candidato de URD.

Fue la democracia venezolana un sistema principalmente bipartidista, donde los candidatos de los partidos AD y COPEI llegaron a concentrar en 1988 el 93,29\% de los votos válidos y en el cual se tuvo como respaldo la Constitución de 1961, que garantizaba la convivencia democrática y el respeto a todos los sectores. Entre 1958 y 1998 se celebraron elecciones presidenciales cada 5 años. Mientras Venezuela afianzaba su democracia, Brasil volvió a los gobiernos militares y a la dictadura, a la represión, el poder volvía al militarismo conservador de extrema derecha, en una época (los años 70) en la cual también surgen o se afianzan dictaduras en Chile, Argentina, Uruguay, Paraguay y Bolivia como parte del Plan Cóndor, sin embargo, a partir del año 74, en Brasil se comienzan a dar pequeños pasos hacia una transición al modelo democrático en el país, un proceso que va a desarrollarse hasta mediados de los años 80 , donde poco a poco se van recuperando libertades, y donde cobran gran importancia los movimientos sociales (sindicatos, movimientos estudiantiles, culturales, etc.) en la lucha por la democracia y los derechos civiles.

Si bien se puede decir que la democracia venezolana estuvo regida por gobiernos de ideología centroizquierdista en su mayoría (principalmente socialdemócratas y socialcristianos), desde la firma del Pacto de Puntofijo ${ }^{3}$, entre AD, COPEI y URD, los sectores cercanos a las ideas comunistas se sintieron apartados. Así, los sectores juveniles de PCV y el grupo más radical de AD, decidieron iniciar una lucha armada tras ser excluidos del Congreso y sentir que la democracia ofrecida no era tal, este movimiento guerrillero surgido en la década de 1960 logró ser controlado, primero a través de enfrentamientos armados que lograron diezmar a los grupos rebeldes, y luego a través de la política de pacificación, que permitió su progresiva incorporación a la vida política,

\footnotetext{
${ }^{3}$ El Pacto de Puntofijo fue un acuerdo de gobernabilidad y respeto al resultado electoral que definía las bases de la República que se quería establecer en temas como: educación, militarismo y economía, se llama así por haberse firmado en Puntofijo, casa de Rafael Caldera
} 
garantizando el pleno respeto a los derechos de los antiguos guerrilleros y, permitiendo el surgimiento del Movimiento al Socialismo (MAS), creado en 1971 por Teodoro Petkoff y Pompeyo Márquez, y que durante dos décadas se fortalecería como el tercer partido más importante en el país, detrás de AD y COPEI. Así, en menos de una década, la lucha armada había sido derrotada y los líderes izquierdistas buscaron espacios institucionales para crecer, incluidas las universidades. La importancia de los grupos estudiantiles de izquierda en la sociedad venezolana, y su creación de un nuevo proyecto, es explicada:

El impacto de las luchas estudiantiles en la sociedad significó la constitución de una "cultura de la protesta callejera", que, por muchos años, hasta los acontecimientos de febrero de 1989, estuvo asociada a los estudiantes y a las universidades.

La derrota de la izquierda en sus intentos por derrocar al gobierno de Betancourt, conllevó a que esa izquierda se concentrara en las universidades. Habiendo perdido sus vínculos orgánicos con sectores obreros y campesinos, los partidos de izquierda parecieron conformarse con "hacer trabajo político" en las universidades. A esto ayudó la misma estructura social venezolana, en la cual existe un grueso sector de clases medias, que desde la llamada generación de 1928 jugó un papel determinante en los acontecimientos políticos del país. Universidades y estudiantes conformaron entonces, en el período 1958-1990, un reducto de oposición al régimen democrático representativo surgido del 23 de enero y consagrado en el Pacto de Punto Fijo. (LÓPEZ SÁNCHEZ, 2006, p. 71).

Estos grupos lideraron los movimientos para “La Renovación” de 1968, que propuso un nuevo modelo universitario, una mayor representación estudiantil en la toma de decisiones y una menor intervención de los partidos políticos. Estos logros perdieron peso después del cierre de la UCV de 19694, en el gobierno de Rafael Caldera, bajo el argumento de que la Universidad operaba como centro de la guerrilla y como depósito de armas, sobre la Renovación se señala

Desde el mismo seno de la comunidad universitaria, surgieron los movimientos de "renovación universitaria" que se orientaban a instrumentar un cambio estructural y curricular en las universidades para poner a la educación superior al servicio de las necesidades nacionales. Estos movimientos se intensificaron desde 1967, y se vincularon con los movimientos estudiantiles del 1968 a nivel mundial, El Mayo Francés y la Primavera de Praga, ambos movimientos contestatarios, extendido por Estados Unidos (Movimiento por la Paz en Vietnam), del cual no escapa la influencia de la Revolución Cultural China.

El clima de renovación universitaria se caracterizó por el cuestionamiento a la estructura organizacional y currículo de las universidades autónomas, que eran las únicas existentes entonces. Lo que el movimiento criticaba era la institucionalidad universitaria misma pues la universidad se había convertido en una institución manipuladora del saber científico-técnico autonomizado y extrañado de las estructuras sociales que lo sustentan; es decir, la sociedad venezolana.

Este saber que se imponían como instrumento de dominación y explotación de esa sociedad generó una dialéctica de cuestionar la universidad tradicional con su didáctica de la enseñanza y un currículo universitario que actuaba

\footnotetext{
${ }^{4}$ La UCV fue allanada en octubre de 1969 y cerrada por dos años, bajo la "Operación Canguro" que buscaba desmovilizar a grupos guerrilleros supuestamente ligados a estudiantes de esta casa de estudio.
} 
como agente reproductor de una estructura clasista. Frente a ese poder cultural científico-técnico exógeno, universal, omnipoderoso, el movimiento universitario le opone la democracia directa, distinta a la representativa, ejercida mediante el asambleísmo y las manifestaciones permanentes de protesta. (VIDOVIC LÓPEZ, 2013, p. 102).

Sin embargo, algunos sectores de la izquierda consideraron que incorporarse al sistema democrático era una traición a los ideales defendidos, registrando pequeños grupos guerrilleros hasta 1983 y algunos actos famosos, como el secuestro del empresario estadounidense William Niehous, perpetrados por líderes de nuevas formaciones como la Liga Socialista. Los grupos más extremos se fortalecen en las universidades, principalmente las públicas, sin embargo, en el escenario electoral nacional tenían poca fuerza, obteniendo algunos pocos diputados. En este entorno surgieron en la UCV los llamados grupos independientes en diferentes facultades y escuelas, comenzando con la de Ingeniería; en 1985, estos grupos reunidos bajo el nombre M80, ganaron la Federación de Centros Universitarios de dicha universidad (las mas grande de Venezuela), derrotando a los representantes de los partidos políticos tradicionales.

\section{Brasil recupera la democracia}

La elección de Tancredo Neves, por medio de una votación indirecta, y la asunción del vicepresidente José Sarney como presidente tras la muerte de Neves poco después de su elección terminaron de sentar las bases de la última etapa de la transición hacia la democracia brasileña, la cual quedaría definitivamente consolidada y establecida con la promulgación de la Constitución de 1988, la cual no sólo establece procedimientos democráticos, como la elección de gobernantes a través del voto universal, directo y secreto y a doble vuelta, sino que también garantiza derechos del pueblo brasileño como el Sistema Único de Salud (SUS), y toma en cuenta temas ambientales y derechos de las poblaciones indígenas, así como marca el fin de la censura en medios de comunicación, recogiendo aspiraciones de amplios sectores y generando profundas esperanzas en distintos actores y grupos de la sociedad brasileña que aspiraban a vivir en una sociedad más justa.

La crisis económica que atraviesa gran parte de los países latinoamericanos durante los años 80, plantea soluciones de corte neoliberal de parte del liderazgo político, enfrentando en casi toda Latinoamérica a los defensores y a los detractores de esas políticas. En las elecciones presidenciales de Brasil de 1989, se enfrentan Fernando Collor de Mello, defensor del modelo neoliberal y Lula Da Silva, crítico a él, resultando ganador el primero, quien, sin embargo, no logra controlar el grave problema inflacionario del país, y terminó siendo destituido en 1992, tras graves acusaciones de corrupción, asumiendo la presidencia Itamar Franco.

\section{La crisis del sistema democrático venezolano}

En diciembre de 1988 es elegido presidente de Venezuela el candidato de AD, Carlos Andrés Pérez, quien ya había ejercido la presidencia del país entre 1974 y 1979, período caracterizado por un gran crecimiento económico y la nacionalización de las empresas petrolera y ferrominera, así como la ejecución de políticas sociales como un plan de pleno empleo y becas para estudios en el exterior a los jóvenes venezolanos conocidas como Fundayacucho. Su carisma, y la certeza de la población de que Pérez garantizaría un retorno a los tiempos de bonanza económica de su 
primer gobierno, la llamada Venezuela Saudita (tras la crisis económica vivida a partir del año 1983) impulsaron el triunfo de Pérez.

Sin embargo, el segundo gobierno de Pérez presenta un plan de gobierno muy distinto al esperado: desplaza en los puestos ministeriales al liderazgo de los partidos políticos que lo apoyaron, para dar protagonismo a un grupo de jóvenes conocidos como los "IESA Boys" , quienes proponen un plan económico de corte neoliberal que incluye la eliminación del subsidio a la gasolina y la privatización de las empresas telefónica y eléctrica.

A menos de un mes de iniciarse la segunda presidencia de Pérez, los días 27 y 28 de febrero de 1989 se registró en Caracas una serie de saqueos contra comercios y negocios, hecho que fue tomado por la izquierda como bandera y reclamo al conjunto de medidas de corte neoliberal propuesto por el presidente Carlos Andrés Pérez unos días antes. Este hecho, conocido como "El Caracazo", que fue severamente reprimido por las fuerzas militares, sumado a los intentos de golpe de estado del 4 de febrero y del 27 de noviembre de 1992 liderados por Hugo Chávez, generaron en la población un deseo de cambio radical que demostraba el agotamiento del sistema democrático. Acosta (2007) explica

El día 27 de febrero de 1989 con la aplicación de una serie de medidas denominado "el paquete del FMI", que comenzaron con el aumento de precios en las tarifas del transporte colectivo, una protesta estudiantil coincidió con una protesta de grupos radicales en torno a los usuarios del transporte público en los terminales de la capital, en los suburbios y en otras ciudades del país. La protesta dejó un saldo de cerca de 400 muertos y pérdidas económicas incuantificables, extendiéndose la protesta al día siguiente por todo el país. Los hechos: saqueos de comercios y la subsiguiente represión por parte de las Fuerzas Armadas para controlarla, al igual que la implementación de la suspensión de garantías y el toque de queda. Años más tarde, otro evento en el plano político institucional deja su huella en la historia contemporánea. El 4 de febrero de 1992, Caracas se estremeció con un intento de golpe de Estado militar liderado por el entonces Teniente Coronel Hugo Rafael Chávez Frías. Hubo revueltas en varios puntos del país con relativo éxito, pero en la capital no fue posible la captura del presidente Carlos Andrés Pérez, la toma del Palacio de Gobierno ni provocar un levantamiento civil. Hugo Chávez asumió la responsabilidad de los hechos y se hizo famoso con aquella afirmación hecha ante la TV diciendo "por ahora no hemos alcanzado los objetivos", llamando a deponer las armas. (ACOSTA, 2007, p. 78).

Una clara señal del descontento político, se vio en las elecciones presidenciales de 1993 con la ruptura del bipartidismo: El expresidente Rafael Caldera, renuncia a su partido COPEI y crea Convergencia, que en alianza con partidos socialistas como el MAS, se impone a los candidatos de los partidos tradicionales: Claudio Fermín (AD) y Oswaldo Álvarez Paz (COPEI). También destaca en estas elecciones el surgimiento del partido obrerista Causa Radical, cuyo candidato, el líder sindical Andrés Velásquez obtiene el cuarto lugar con una votación muy cercana a los tres primeros y logra obtener una votación muy alta en la ciudad de Caracas.

\footnotetext{
${ }^{5}$ El Instituto de Estudios Superiores en Administración es un instituto con sede en Caracas que ofrece diversos cursos de maestría en el área, varios de los jóvenes tecnócratas ligados al proyecto de Pérez tenían relación con el IESA como egresados o profesores. El nombre "IESA Boys" marca similitud con los "Chicago Boys" que implementaron políticas de corte neoliberal durante la dictadura de Pinochet en Chile.
} 
La gestión de Caldera, electo en 1993, fue de inestabilidad política, tras dos años de fracasos económicos, decidió junto al ministro Petkoff (antiguo líder guerrillero como se indicó previamente) tomar algunas medidas de corte liberal, que permitieron recuperar la economía durante sus dos últimos años de gobierno, pero a medida que se acercaban las elecciones de 1998 aumentaba el descontento popular, llevando finalmente al triunfo del militar golpista Hugo Chávez en las elecciones de aquél año, en una elección polarizada entre dos partidos nuevos: El Movimiento Quinta República (MVR), partido socialista creado por Chávez y Proyecto Venezuela (PV), partido de derecha liderado por el empresario y antiguo gobernador del Estado Carabobo (estado industrial en el centro de Venezuela) Henrique Salas Römer.

\section{El afianzamiento de la izquierda}

A mediados de los 90, Brasil logra la estabilidad macroeconómica a través del Plan Real de Fernando Henrique Cardoso, quien gobierna el país hasta el año 2002, sin embargo, las demandas sociales de sectores excluidos no son totalmente satisfechas y los reclamos aumentan.

En las elecciones de 2002, el líder sindicalista Luiz Inácio Lula Da Silva es electo presidente, en medio de un viraje a la izquierda experimentado por gran parte de América Latina, sus políticas inclusivas, oportunidades educativas, programas de respaldo a las minorías, programas de apoyo a los más pobres, respaldo al sistema educativo, entre otras, le ganan el aprecio y el apoyo de la mayoría del pueblo brasileño, incluyendo varios adversarios y el reconocimiento internacional, mientras le aseguran un segundo mandato que profundizará los cambios, en medio de un entorno de estabilidad económica.

Mientras tanto en Venezuela, y bajo una nueva constitución, Chávez ganaría las elecciones de los años 2000, 2006 y 2012, y gobernaría el país hasta su muerte en 2013. La esperanza inicial que representó Chávez y el gran apoyo con el que contaba se fueron desvaneciendo poco a poco a partir del año 2001, llevando a la realización de un referéndum revocatorio en 2004. Chávez, que cuatro meses antes del referéndum era minoría en las encuestas por primera vez desde 1998, implementó una serie de programas sociales, llamados “Misiones", planes que incluían programas de alfabetización, becas a jóvenes estudiantes, mejoras en el sistema de salud, creación de puestos de atendimiento primario en zonas populares, etc, lo que le permitió ganar el referéndum y evitar ser revocado.

El periodo presidencial que Chávez inició en 2007, tras un amplio triunfo en diciembre de 2006 profundizó en la aplicación del modelo socialista, el cual se ve apoyado por el incremento de las "misiones" gracias al aumento en los precios del petróleo, pero también implica en el cierre de medios de comunicación (el caso más representativo: el cierre de Radio Caracas Televisión (RCTV) en 2007), y el aumento de la represión.

Tras la muerte de Chávez, se realizan elecciones en 2013, en las cuales resulta electo Nicolás Maduro, del Partido Socialista Unido de Venezuela (PSUV, partido sucesor del antiguo MVR fundado por Chávez) sobre Henrique Capriles Radonski (MPJ), en unas elecciones donde la diferencia de votos, de acuerdo a los resultados oficiales, fue menor al $2 \%$.

El periodo 2015-2018, queda marcado en Venezuela por una profunda crisis económica, el aumento de la represión, el incremento de la migración y de la cantidad de presos políticos, una inflación más alta que cualquiera conocida previamente en América Latina, y el debilitamiento continuo de las instituciones. Si bien en la crisis se evidencia la responsabilidad del gobierno en temas como: la caída en la producción petrolera (en 2019 se produce una cuarta parte de lo que 
se producía en 2009), la politización de cargos técnicos en la empresa petrolera, la persecución a empresarios y la expropiación de fábricas que luego han sido manejadas de forma ineficiente, también algunos factores externos han agravado la misma, como la caída en los precios del petróleo. Las sanciones que Estados Unidos y otros gobiernos han aprobado contra distintos funcionarios del gobierno de Maduro, o ligados a él a partir de 2015, son posteriores al inicio de la crisis, pero algunos analistas y líderes políticos, señalan que las mismas han profundizado el problema económico del país, especialmente a partir de 2019, cuando las sanciones se dirigen a PDVSA (empresa petrolera del estado venezolano) y a algunas de sus embarcaciones, si bien, la mayoría de las sanciones van dirigidas a funcionarios acusados de delitos como narcotráfico, violaciones a los Derechos Humanos o debilitamiento de la institucionalidad democrática. Las posibles repercusiones de sanciones que afectaran el tema petrolero habían sido anticipadas un año antes por Colmenares al señalar su impacto económico y su planteamiento político:

Estados Unidos es el principal socio comercial de Venezuela, por lo que se supondría que la aplicación de sanciones económicas tendría un profundo impacto en la maltrecha economía venezolana. Ahora bien, las sanciones económicasy laslimitaciones paracomerciarconciertasempresas venezolanas no han tocado la explotación petrolífera. El argumento del gobierno de Trump es que no pretende causar perjuicios a la sociedad venezolana. Si las sanciones de Trump y su gobierno no van acompañadas de una visión a largo plazo y una respuesta multilateral, además de un compromiso más firme con las instituciones regionales y foros de concertación -además de presiones o incentivos sobre los pequeños Estados insulares del Caribe que aún apoyan a Maduro-, poco se promoverá la institucionalidad democrática de Venezuela y Maduro se fortalecerá con las fanfarronadas del volátil Trump. (COLMENARES, 2018, p. 24).

\section{La actualidad de ambos países}

En 2018 Maduro convoca unas polémicas elecciones presidenciales, si bien en aquél año correspondía realizar elecciones presidenciales, las mismas se realizan 6 meses antes de lo previsto, y los sectores opositores denuncian que: se inhabilitó a los dos principales líderes de la oposición de acuerdo a las encuestas del momento: Leopoldo López y Henrique Capriles Radonski, se ilegalizaron los principales partidos de oposición: Primero Justicia (PJ), Voluntad Popular (VP), Acción Democrática (AD) y Un Nuevo Tiempo (UNT), se eliminaron una serie de garantías y auditorías electorales, y se otorgó el proceso de transmisión y totalización a una empresa que fue señalada como afín al gobierno, tras la denuncia de diversas irregularidades de parte de Smarmatic (empresa que solía prestar el apoyo técnico al órgano electoral). En estas elecciones Maduro gana al antiguo gobernador del estado Lara Henri Falcón, sin embargo, se observa un alto índice de abstención como protesta a las condiciones electorales, por lo cual los resultados son desconocidos por un amplio sector de la población venezolana, el Parlamento Venezolano (de amplia mayoría opositora y elegido en 2015) y por más de 60 gobiernos a nivel internacional.

A Lula, en Brasil, le sucede Dilma Rousseff, también del Partido de los Trabajadores (PT), quien continúa con los planes sociales de Lula y goza de gran popularidad, principalmente en sus primeros años, aunque enfrenta algunas protestas de calle y después de su segunda elección, es destituida por el Congreso acusada de participar en una trama de corrupción, y cediendo el 
poder al vicepresidente Michel Temer, en una acción que gran parte del pueblo brasileño, diversos medios brasileños e internacionales, académicos e investigadores consideran un golpe de estado.

Mientras tanto, en 2018, es elegido como presidente Jair Bolsonaro, candidato populista de derecha, que, con un discurso de polarización, y ante la imposibilidad de participar Lula, quien era favorito en las encuestas, logra aglutinar una gran cantidad de apoyos, generando varias dudas sobre el futuro político de Brasil.

\section{Movimientos estudiantiles en Venezuela}

Claramente inspirados por los cambios que se daban en el mundo en las dos primeras décadas del siglo XX, la influencia de sus maestros en el Liceo Caracas, principalmente de Don Rómulo Gallegos, aunque también cercanos a ideologías marxistas, muy de moda tras la revolución rusa, los jóvenes estudiantes de la Universidad Central de Venezuela en el año 1928, marcaron una etapa en la historia del movimiento estudiantil venezolano y de la democracia en el país.

Este grupo, la llamada "Generación del 28”, aprovechó las festividades de la semana del estudiante para impulsar una serie de protestas a través de discursos, y actos simbólicos, que aprovecharon para generar fuertes críticas a la dictadura de Gómez. Apenas unas pocas semanas después aquellos jóvenes serían encarcelados o exiliados. De este grupo de jóvenes nacerían algunos de los partidos más importantes en Venezuela en el siglo XX: Acción Democrática (AD) y Unión Republicana Democrática (URD).

Tras los 10 años de dictadura militar, principalmente los seis liderados por el General Marcos Pérez Jiménez, y después del regreso del exilio, en 1958 se inicia el periodo democrático más largo en la historia del país, AD y URD son protagonistas de los cambios y de la modernización del país, los dos primeros presidentes electos en este periodo por el voto popular son Betancourt y Leoni, antiguos protagonistas de los hechos del 28. Como se puede ver, la generación del 28 supo proponer un proyecto de país, llegó a gobernar Venezuela, y mantuvo cercanía con otros movimientos. Junto a ellos, el partido COPEI fundado por Rafael Caldera también fue protagonista principal de aquél período democrático. Caldera había sido líder estudiantil de los estudiantes de educación media en 1936 y desde ese momento se proyectó a nivel nacional como líder de ideas más cercanas a la tradición católica.

Los años 60 son marcados por importantes movimientos estudiantiles simpatizantes de la revolución cubana. Las protestas contra la naciente democracia y el surgimiento de la guerrilla urbana de la cual forman parte jóvenes estudiantes, llevan al cierre de la Universidad Central de Venezuela (UCV) en 1969, frenando además el proceso de Reforma Universitaria propuesto por amplios sectores de jóvenes organizados en 1968.

En los años 70 y 80, tras la reapertura de la UCV y el surgimiento de nuevas universidades se observa un amplio dominio de grupos ligados a la izquierda en la representación estudiantil, las elecciones estudiantiles enfrentan básicamente a grupos socialistas democráticos (ligados al MAS) contra grupos socialistas radicales y defensores de la rebelión popular cercanos a los partidos políticos Liga Socialista y Bandera Roja.

La crisis económica que se siente en Venezuela desde 1983, la disminución de credibilidad en los partidos y la asociación que dentro de la juventud se hace entre algunos líderes políticos y su contraparte en las universidades, origina un progresivo fortalecimiento de los grupos más radicales de la izquierda, permitiendo el surgimiento de grupos no vinculados a partidos, de esta forma, a mediados de los años 80, el M80 se alza con el triunfo en las elecciones estudiantiles de la 
UCV. Muchos de estos líderes, ocuparán puestos importantes en el surgimiento del Movimiento Quinta República (MVR), tanto en funciones de parlamentarios como de ministros o de operadores políticos, principalmente algunos egresados de la UCV.

El nuevo siglo, trae una gran polarización en el país, y se encuentra con movimientos estudiantiles. La situación política de Venezuela la resume Tilly (2007), haciendo énfasis en los primeros años del gobierno:

Cuando Chávez llegó al poder en 1999, los enfrentamientos en las calles entre sus seguidores y sus oponentes se aceleraron. La visita del nuevo jefe de Estado a la Cuba oficialmente socialista de Fidel Castro más tarde ese mismo año escenificó su plan de transformar globalmente el gobierno y su lugar en el mundo. Comenzó a presionar a la compañía petrolera estatal, Petróleos de Venezuela, para obtener más ingresos y reducir progresivamente su legendaria autonomía. Chávez también revivió la vieja reivindicación popular venezolana por un trozo de la Guyana Occidental. Venezuela derivó hacia un nuevo estadio de lucha por el control del futuro del país. Durante los siete años siguientes, Chávez empleó su control sobre los ingresos del petróleo para consolidar su poder, cercenar a su oposición, promocionar el populismo en cualquier otro lugar de América Latina e incluso resistirse a unos Estados Unidos cada vez más hostiles. Sobrevivió al golpe de Estado auspiciado por los EEUU en 2002, coordinó la resistencia a la compañía nacional petrolera de 2002 a 2003, una huelga general durante el mismo periodo y un referéndum revocatorio apoyado por los EEUU en 2004. Paso a paso ha respondido con una represión endurecida. El legislativo dominado por Chávez limitó al Tribunal Supremo, amplió las prohibiciones por injurias o faltas de respeto al presidente e intensificó la vigilancia de los medios de comunicación de masas. Entre tanto, los tribunales han perseguido a un número creciente de opositores al régimen. Aun cuando ha seguido disfrutando de un apoyo sustantivo entre los numerosos pobres de Venezuela, al igual que la Rusia de Putin o la Argelia de Buteflica, Chávez se ha sostenido en la riqueza generada por el petróleo del país para evitar el consenso popular. (TILLY, 2010, p- 209-210).

Las protestas del año 2002, permiten el resurgimiento del movimiento estudiantil, sin embargo, la naciente organización se ve opacada por el protagonismo de líderes políticos de oposición y de sectores empresariales, dueños y figuras de medios de comunicación y líderes sindicales. Sin embargo, poco a poco los estudiantes van ganando notoriedad hasta llegar al año 2007.

El 28 de mayo de 2007, después del cierre del canal de televisión RCTV, se registraron distintas protestas en las entradas de las universidades más importantes de Caracas, La movilización aumentó en los días siguientes, y cada día se evidenció una mayor organización, además los líderes de las distintas instituciones lograron establecer actividades en conjunto, y muchos de sus dirigentes, entre los que destacaban Stalin González, Freddy Guevara, Yon Goicoechea, Juan Andrés Mejía, Manuela Bolívar, Juan Guaidó, Douglas Barrios, Daniela García Muller, Omar Arenas y Ricardo Sánchez entre otros, logran posicionarse. Sobre este movimiento, señala Uzcátegui (2014):

Quienes rechazaron la medida se aglutinaron bajo el nombre genérico de «estudiantes por la libertad», lo cual incluía no solo a los alumnos de las universidades públicas sino-novedosamente-también a los de las instituciones privadas. Los «estudiantes por la libertad» emergieron como una «oposición leal» enmarcando sus discursos y demandas por la libertad de expresión 
y por el derecho a la participación dentro de la Constitución venezolana, aceptando de forma tácita la legalidad y legitimidad del gobierno de Chávez sin pretender desmantelar el aparato gubernamental. Las movilizaciones estudiantiles tuvieron una sobreexposición mediática, por lo que la reacción gubernamental fue trasladar el conflicto callejero a debates institucionalizados entre estudiantes opositores y bolivarianos. (UZCÁTEGUI, 2014, p. 161).

Estos jóvenes reconocidos como “La Generación 2007” logran levantar la bandera de la libertad de expresión, logran importante presencia mediática y se convierten en referentes políticos de la sociedad venezolana, ganando credibilidad y liderando la campaña contra la reforma a la Constitución propuesta por Hugo Chávez en 2007, que finalmente se convertiría en la primera derrota electoral del militar. Como contraparte a la Generación de 2007, el chavismo proyectó un grupo de estudiantes donde destacaban Héctor Rodríguez (elegido en 2017 gobernador del Estado Miranda, uno de los más importantes del país y tradicionalmente opositor al chavismo), Robert Serra, Andreína Tarazón, Libertad Velasco, César Trompiz, entre otros, grupo al que Chávez bautizó como "Hijos de la Revolución”.

Posteriormente los estudiantes también lideraron importantes movimientos de calle en 2014 y 2017. En 2019, tras unas polémicas elecciones, Juan Guaidó, antiguo líder estudiantil de la UCAB, se convierte en líder de la oposición, tras asumir la presidencia del Poder Legislativo y juramentarse como presidente encargado, de acuerdo a lo establecido en la Constitución ante la ausencia definitiva del Presidente, consecuencia del desconocimiento al proceso de 2018, en medio de una tensa situación política.

\section{Movimiento Estudiantil en Brasil}

No se puede hablar de un verdadero movimiento estudiantil en Brasil hasta 1937, cuando la Unión Nacional de los Estudiantes (UNE) es fundada, que será el punto de referencia de las acciones estudiantiles de aquella época hasta hoy.

Después de la Segunda Guerra Mundial, la campaña "El petróleo es nuestro" será impulsada por la UNE. En el contexto global, el hidrocarburo es vital para la industrialización y el desarrollo de los diferentes países, así como en el contexto de América Latina, también es visto como una cuestión de defensa de la soberanía. Sobre esta campaña, explica Machado (2015):

La campaña, que movilizó a diversas entidades estudiantiles y a otros grupos sociales (como militares y periodistas), materializó la discusión de la emancipación económica de Brasil a partir de la nacionalización de las riquezas naturales, así como su adecuada explotación por el propio Estado. Para Roberto Gusmão, presidente de la UNE en 1947 el movimiento en torno al petróleo fue el punto de discusión encontrado por el movimiento estudiantil para involucrar a los estudiantes en la participación política; la UNE en sus circulares estimulaba a todas las demás entidades a profundizar en tal debate y obtuvo la adhesión de diversos grupos sociales interesados en la cuestión nacional. (MACHADO, 2015, p. 62-63).

Uno de los puntos de mayor protagonismo de la UNE se observa en los años 60 , cuando se convierte en uno de los más fuertes baluartes de la lucha contra la dictadura militar que sucedió a Goulart, pero también sufren severas persecuciones y ultrajes con cientos de líderes presos e 
importantes movimientos de protesta después de los abusos cometidos por el gobierno, como el asesinato de Edson Luis. Sobre las banderas de esta época, dice Machado (2015):

La lucha política contra la dictadura militar volvió a predominar en el discurso del movimiento estudiantil, y los lemas "abajo de la dictadura" o "abajo el imperialismo yanqui" representaron el nuevo movimiento estudiantil proveniente de la resistencia a los abusos del régimen militar en los espacios universitarios.

Por otro lado, en 1968, período marcado por una ola global de revueltas, el movimiento estudiantil brasileño se integró a las rebeldías juveniles del planeta; conoció otros movimientos existentes que asociaron y desarrollaron movimientos locales con una visión global y con deseos libertarios en común. El imperialismo estadounidense (que estaba siendo observado internacionalmente con la guerra en Vietnam), la solidaridad con la revolución cubana y la posición a favor de la independencia política y económica de los países de América, así como el cuestionamiento de los valores de la sociedad burguesa e industrial fueron las cuestiones que los movilizaron (MACHADO, 2015, p. 72).

Almada (2016), señala sobre esta época, explicando el inicio de la represión, y la brutalidad de las acciones de la dictadura:

As lutas estudantis de 1968 foram demarcadas por episódios pontuais em situações de tensão com as forças policiais (VALLE, 2008). A morte do estudante Edson Luiz de Lima Souto, em 28 de março, no Restaurante do Calabouço da Universidade Federal do Rio de Janeiro (UFRJ) é o primeiro e emblemático caso. Ele pode ser compreendido num contexto imediato de fortalecimento da participação dos estudantes no interior das universidades. Aquelas manifestações, organizadas pela Força Unida dos Estudantes do Calabouço (FUEC), criticava as precárias condições do restaurante e o aumento do valor das refeições. Durante uma assembleia estudantil, o batalhão de choque da Polícia Militar invadiu o restaurante e fez disparos de metralhadora, matando o estudante de 16 anos. Com esse fatídico episódio, se seguiram várias manifestações de solidariedade, conduzidas por centros acadêmicos e diretórios. (ALMADA, 2016, p. 130-131).

Después de más de una década de persecución y tortura, prisión e incluso asesinato de varios líderes, a finales de los años 70, la UNE repite su papel de protagonista luchando por la democracia, complementado además con varios grupos de estudiantes a través de presentaciones pastorales y artísticas que se unirán a la lucha por un nuevo sistema que garantice el respeto de los derechos de los ciudadanos. Después del retorno al sistema democrático, las demandas educativas son la principal bandera del movimiento estudiantil brasileño, que, sin embargo, parece un poco desacreditado, cuando varios de sus líderes privilegian el propio interés político partidista.

Un momento importante del movimiento estudiantil brasileño se vive en el año 1992, cuando los "Caras pintadas" se convierten en símbolo de resistencia contra el gobierno de Collor de Melo, mientras se discute su destitución como presidente. Sobre este movimiento y su importancia se señala:

Inúmeras manifestações em favor do impeachment de Collor agitaram o cenário político brasileiro entre os meses de agosto e setembro de 1992.0 então presidente era acusado de estar envolvido em uma série de denúncias de 
corrupção que eram investigadas por uma Comissão Parlamentar de Inquérito (CPI). Por esse motivo, milhares de pessoas saíram às ruas das principais cidades do País protestando contra o governo federal. (ALVES y BONI, 2011, p.168).

La llegada del nuevo siglo, y del ascenso al poder de Lula, permite la implementación de muchas propuestas históricas del movimiento estudiantil, por eso, aunque no disminuye su organización, si lo hace su desempeño y fuerza en la protesta. Movimiento estudiantil, toma como bandera principal, la educación pública y gratuita y la libertad en la educación.

Como se puede ver desde su inicio, y a lo largo de la historia, el movimiento estudiantil brasileño ha sido asociado a ideologías de izquierda, pero no de forma dogmática, sino en cuanto a defender principios de igualdad, defensa de medios democráticos y de lucha por la educación gratuita y defensa de los derechos humanos. De la misma forma, sus movilizaciones sociales permitieron que fueran protagonistas de los más importantes cambios sociopolíticos vivenciados en Brasil en el último siglo. La UNE representa una de las estructuras estudiantiles más organizadas en el contexto latinoamericano, ya que no sólo tiene una unión nacional, sino que existen representaciones también organizadas a nivel estadual.

Los recortes presupuestarios a las Universidades y en las becas en 2019, hacen notar marchas en contra de las políticas del nuevo gobierno y presagian la reorganización del movimiento estudiantil brasileño.

\section{Semejanzas y diferencias entre los movimientos estudiantiles de Brasil y Venezuela}

Aclarando que el análisis de una sola categoría resulta insuficiente para caracterizar adecuadamente los movimientos estudiantiles, aunque sí permite establecer algunas comparaciones claras, se determinarán las semejanzas observadas al estudiar los entornos sociopolíticos de Venezuela y Brasil.

En primer lugar, destaca el carácter contestatario, el deseo de cambio, la oposición a los sistemas establecidos. Este carácter se hace más evidente y se ve fortalecido especialmente en momentos de mayor represión y amenaza a la población, como fue el caso de Venezuela en 1928, 1958 y 2007, o el de Brasil en 1967. También, el partir del tema educativo, pero proyectado a la sociedad, reclamando cambios generales desde un sector particular, pidiendo cambios profundos, incluso de modelo de país, es otra condición que comparten ambos grupos de estudio.

Si bien el estudio de los movimientos estudiantiles supone que se pueden obtener algunas características generales, entre los movimientos de ambos países se observan algunas diferencias importantes. Para comenzar, se puede señalar, que el movimiento venezolano, ha sido generador de grandes liderazgos nacionales, siendo parte activa de todos los gobiernos desde mediados del Siglo XX, en funciones de presidentes o ministros, mientras que los grandes liderazgos del movimiento brasileño parecen encontrar mayores dificultades para ingresar a la élite política del país.

También se puede observar que el auge de los movimientos estudiantiles se da con muchos años de diferencia. Mientras en Venezuela desde el año 1928 el estudiantado es referente claro del desarrollo del país, en Brasil, su punto culminante llegará en 1968 (si bien existía un movimiento organizado desde los años 30). 
De las fuentes consultadas se puede observar que la percepción que tiene la sociedad de los líderes estudiantiles también es distinta. Mientras en la sociedad venezolana, los líderes estudiantiles son percibidos como genuinos representantes del pueblo, y como voz de clases medias y bajas, en Brasil, tradicionalmente han sido percibidos como representantes de una clase media distante a la población de bajos recursos.

Cabe destacar la organización: en Brasil existen instancias nacionales y estaduales de organización estudiantil, facilitando los canales de comunicación y la elaboración de estrategias de lucha. En Venezuela, si bien en algunos momentos (como en 2007) se ha logrado una organización fuerte, no existe claramente una instancia de organización nacional, teniendo lugar algunas protestas espontáneas o pudiendo existir diferencias entre las acciones y propuestas de distintas universidades.

Finalmente, estudiando los factores externos de mayor influencia en cada movimiento, se observa que, en Venezuela, la reforma de Córdoba y la revolución rusa, son elementos determinantes, mientras que, en Brasil, tienen mayor influencia el Mayo Francés y los movimientos pacifistas de los años 60.

\section{Conclusión}

Se pudo verificar que, aunque los dos países vivieron procesos similares históricos, aunque no siempre simultáneos, así la transición a la democracia, marcada por períodos de dictadura militar y fuerte represión e intentos de transición fallidos ha estado presente en los dos países.

Se tienen marcadas diferencias en la importancia y el impacto de los movimientos estudiantiles en ambos países, si bien el movimiento brasileño presenta mayor organización, al tener estructura nacional y estadual definida, se observa que el movimiento venezolano tiene mayor impacto social y política, habiendo proyectado a gran cantidad de presidentes, ministros y gobernadores de diversas ideologías.

Se verificó la utilidad de las categorías propuestas por Gohn (1997) para el estudio realizado, por lo cual se sugiere usar este estudio como base para futuros estudios relativos a otras categorías propuestas por la autora.

\section{Referências}

ACOSTA, Y. J. La protesta política en Venezuela (2001-2007). Psicología- Revista de la Escuela de Psicología, Caracas, v. XXVI, n. 2, p. 74-98, 2007. ISSN 1316-0923.

ALMADA, P. A cultura política de 68: Reflexões sobre a resistência estudantil em Brasil e Portugal. Mediações, Londrina, v. 21, n. 2, p. 123-143, Julio- Diciembre 2016. ISSN 10.5433/2176-6665.2016v21n 2 p123.

ALVES, F. A.; BONI, P. C. Os “caras-pintadas”: o fotojornalismo como elemento construtor da memória. Conexão - Comunicação e Cultura, Caxias do Sul, v. 10, n. 19, p. 161-178, Enero- Juniio 2011.

BARILE, J. E. El Brasil de 1889-1930: El regionalismo en el federalismo republicano. Revista de Informação Legislativa: RIL, Brasilia, p. 33-43, Diciembre 2017.

BERNARD, B. Nacimiento y escisión del movimiento popular en Venezuela (1928-1940). Frónesis, Maracaibo, v. 1, n. 1, p. 19-54, 1994. ISSN 1315-6268. 
COLMENARES, A. Las relaciones de Venezuela con Estados Unidos en la era de Trump. Foreign Affairs, Ciudad de México, v. 1, p. 17-24, Enero- Marzo 2018.

GOHN, M. D. G. Teorias dos Movimentos Sociais: Paradigmas clássicos e contemporãneos. São Paulo: Edições Loyola, 1997.

LÓPEZ SÁNCHEZ, R. Los movimientos estudiantiles en Venezuela, 1958-1990. Historia Actual, Cádiz, n. 10, p. 71-85, Junio 2006. ISSN 1696-2060.

MACHADO, O. L. Un siglo de movimento estudantil en Brasil. In: MARSISKE, R. Movimientos estudiantiles en la historia de América Latina IV. Ciudad de México: UNAM, 2015. Cap. I, p. 57-80.

REY, J. C. La democracia venezolana y la crisis del sistema populista de conciliación. Revista de Estudios Políticos (Nueva Época), Madrid, n. 74, p. 533-578, Octubre- Diciembre 1991. ISSN 0048-7694.

TILLY, C. Democracy. Madrid: Ediciones AKAL, 2010.

UZCÁTEGUI, R. Movilizaciones estudiantiles en Venezuela: Del carisma de Chávez al conflicto en redes. Nueva Sociedad, Caracas, n. 251, p. 153-165, Mayo-Junio 2014. ISSN 0251-3552.

VIDOVIC LÓPEZ, J. F. Antecedentes de las universidades nacionales experimentales y nacimiento de la UNERMB. Contribución para la reconstrucción de la historia de la universidad. Perspectivas, Maracaibo, v. 1, n. 1, p. 99-116, Enero-Abril 2013. ISSN 2343-6271. 